ORIGINAL ARTICLE

\title{
Effect of extended morning fasting upon ad libitum lunch intake and associated metabolic and hormonal responses in obese adults
}

\author{
EA Chowdhury ${ }^{1}$, JD Richardson ${ }^{1}$, K Tsintzas $^{2}$, D Thompson ${ }^{1}$ and JA Betts ${ }^{1}$
}

\begin{abstract}
BACKGROUND/OBJECTIVES: Breakfast omission is positively associated with obesity and increased risk of disease. However, little is known about the acute effects of extended morning fasting upon subsequent energy intake and associated metabolic/regulatory factors in obese adults.

SUBJECTS/METHODS: In a randomised cross-over design, 24 obese men $(n=8)$ and women $(n=16)$ extended their overnight fast by omitting breakfast consumption or ingesting a typical carbohydrate-rich breakfast of $2183 \pm 393 \mathrm{~kJ}$ (521 $\pm 94 \mathrm{kcal}$ ), before an ad libitum pasta lunch $3 \mathrm{~h}$ later. Blood samples were obtained throughout the day until $3 \mathrm{~h}$ post lunch and analysed for hormones implicated in appetite regulation, along with metabolic outcomes and subjective appetite measures.

RESULTS: Lunch intake was unaffected by extended morning fasting (difference $=218 \mathrm{~kJ}, 95 \%$ confidence interval $-54 \mathrm{~kJ}, 490 \mathrm{~kJ}$; $P=0.1$ ) resulting in lower total intake in the fasting trial (difference $=-1964 \mathrm{~kJ}, 95 \%$ confidence interval $-1645 \mathrm{~kJ},-2281 \mathrm{~kJ}$; $P<0.01)$. Systemic concentrations of peptide tyrosine-tyrosine and leptin were lower during the afternoon following morning fasting $(P \leqslant 0.06)$. Plasma-acylated ghrelin concentrations were also lower following the ad libitum lunch in the fasting trial $(P<0.05)$ but this effect was not apparent for total ghrelin $(P \geqslant 0.1)$. Serum insulin concentrations were greater throughout the afternoon in the fasting trial $(P=0.05)$, with plasma glucose also greater $1 \mathrm{~h}$ after lunch $(P<0.01)$. Extended morning fasting did not result in greater appetite ratings after lunch, with some tendency for lower appetite $3 \mathrm{~h}$ post lunch $(P=0.09)$.

CONCLUSIONS: We demonstrate for the first time that, in obese adults, extended morning fasting does not cause compensatory intake during an ad libitum lunch nor does it increase appetite during the afternoon. Morning fasting reduced satiety hormone responses to a subsequent lunch meal but counterintuitively also reduced concentrations of the appetite-stimulating hormoneacylated ghrelin during the afternoon relative to lunch consumed after breakfast.
\end{abstract}

International Journal of Obesity (2016) 40, 305-311; doi:10.1038/ijo.2015.154

\section{INTRODUCTION}

Regular breakfast omission is associated with greater risk of obesity, $^{1,2}$ prospective weight gain, ${ }^{3}$ type 2 diabetes ${ }^{4,5}$ and coronary heart disease. ${ }^{6}$ Randomised controlled trials have examined whether breakfast consumption relative to extended fasting is causally related to weight change in free-living overweight/obese individuals. ${ }^{7,8}$ Owing to the limitations of quantifying energy intake under free-living conditions, ${ }^{9}$ various laboratory-based studies have also examined acute energy intake and immediate metabolic responses to differing breakfast compositions/quantities. ${ }^{10-17}$ However, the comparison of these acute responses in obese adults under laboratory-controlled conditions remain to be examined in relation to the more fundamental comparison between extended morning fasting and breakfast consumption.

Laboratory paradigms allow careful examination of the metabolic consequences of meal omission and can highlight potential mechanisms that cannot be studied in free-living settings. The use of an ad libitum lunch meal also allows some insight into the effects of different morning intakes on immediate energetic compensation that set meals do not allow. Some laboratory studies have quantified ad libitum energy intake following breakfast omission in lean individuals, ${ }^{18-22}$ with the majority of studies indicating additional intake at lunch ${ }^{18,19,21,22}$ but less clear evidence for the effects upon intake at subsequent meal/snacking opportunities. $^{18,22}$ In all but one investigation ${ }^{20}$ where a relatively small ( $10 \%$ of daily energy requirements) breakfast was consumed, subsequent feeding has been insufficient to compensate for the breakfast omitted. ${ }^{18,19,21,22}$ However, there is no evidence pertaining to immediate energetic compensation following breakfast omission in obese individuals. A recent study has examined metabolic and hormonal responses to extended fasting compared with breakfast consumption in overweight individuals. ${ }^{23}$ However, this was in response to a set lunch meal, so immediate energetic compensation was not examined. It is therefore currently unknown the degree to which obese individuals compensate for morning fasting and importantly, the metabolic and hormonal consequences of doing so.

It cannot be assumed that the responses of obese individuals will be the same as lean individuals. Previous studies contrasting obese and lean counterparts have highlighted several relevant differences that might contribute to divergent findings in the two groups. For example, obese individuals have delayed satiation to feeding, with greater energy intake before reaching maximum satiation. ${ }^{24}$ This discrepancy in satiation may partly be influenced by differences in appetite-regulating hormones. It has been

${ }^{1}$ Department for Health, University of Bath, Bath, UK and ${ }^{2}$ School of Life Sciences, Queen's Medical Centre, University of Nottingham, Nottingham, England. Correspondence: Dr JA Betts, Department for Health, University of Bath, Bath BA2 7AY, UK.

E-mail: J.Betts@bath.ac.uk

Received 12 May 2015; revised 25 June 2015; accepted 3 August 2015; accepted article preview online 17 August 2015; advance online publication, 8 September 2015 
reported that peptide tyrosine-tyrosine (PYY; a hormone implicated in satiety ${ }^{25}$ ) concentrations are lower postprandially in obese as opposed to normal-weight individuals, despite greater intake during an ad libitum buffet lunch. ${ }^{26}$ This attenuation of PYY release has been implicated in the reduced satiety induced by meals in obese individuals. ${ }^{27}$ Furthermore, the usual suppression of ghrelin (an appetite-stimulating hormone ${ }^{28}$ ) in response to feeding in lean individuals is reduced ${ }^{29}$ or potentially even completely abolished $^{30}$ in obese individuals. Although these studies have established differences in hormonal regulation of appetite between lean and obese individuals, little is known about the hormonal responses of obese individuals to feeding after an extended morning fast and a subsequent meal. Owing to the features of hormonal regulation of appetite in obese individuals outlined above, the potential for a prior meal (in this instance a typical breakfast) to reduce subsequent intake might be inhibited but this requires examination.

To this end, the present study examined energy intake, as well as metabolic and hormonal responses to acute morning fasting in obese individuals. It is hypothesised that extended morning fasting will not result in greater ad libitum lunch intake than breakfast consumption.

\section{PARTICIPANTS AND METHODS}

\section{Participants}

Twenty-four healthy obese men $(n=8)$ and women $(n=16)$ aged $25-58$ years took part in this study. Written informed consent was obtained from all participants, with the Ethical Approval for the study obtained from the NHS Bristol Research Ethics Committee. The study is registered with Current Controlled Trials (ISRCTN31521726). Participants were firstly deemed eligible to participate if they had a body mass index of $\geqslant 30 \mathrm{~kg} \mathrm{~m}^{-2}$ and then later classified as obese based upon dual energy X-ray absorptiometry-derived fat mass indices of $\geqslant 9 \mathrm{~kg} \mathrm{~m}^{-2}$ (men) and $\geqslant 13 \mathrm{~kg} \mathrm{~m}^{-2}$ (women). ${ }^{31}$ The study was part of a wider programme of work. ${ }^{32}$ The sample size for this study was based on estimates for the programme of work as described previously. ${ }^{32}$ In brief, those estimates were determined by the number of participants required to detect differences in free-living physical activity and energy intake between two independent experimental groups ( $n \sim 14$ per group). Therefore, the sample size of this investigation $(n=24)$ is sufficient to detect any meaningful responses of the more tightly controlled laboratory-based parameters assessed within participants using the repeated measures crossover design employed. Participants reported being weight stable ( $\pm 2 \%$ body mass within the past 6 months), followed a standard sleep-wake cycle (for example, no shift workers) and did not anticipate changes in lifestyle (for example, diet/exercise) during the study period. Participants were free from metabolic disorders and were not taking any medications known to affect appetite regulation, with those participants that were pre-menopausal either menstruating regularly, or following their chosen contraceptive method (that is, pill, implant) for $>6$ months. Pre-menopausal women were tested during days 3-10 of the menstrual cycle to avoid any effect of menstrual cycle phase on appetite. The cohort comprised of a mixture of regular breakfast consumers and non-consumers (classified based on $>50 \mathrm{kcal}$ intake within $2 \mathrm{~h}$ of waking on $\geqslant 4$ days of the week). Characteristics of participants are presented in Table 1 .

\section{Study methodology}

In brief, the obese participants recruited for the current investigation undertook a randomised, counterbalanced cross-over study design comprising two laboratory-based-feeding trials as previously described in full for lean participants ${ }^{21}$ and following general methods as described in the protocol for the wider programme of work. ${ }^{32}$

\section{Protocol for laboratory visits}

Prior to their first visit to the laboratory, participants maintained a $48 \mathrm{~h}$ food and drink record, which they subsequently replicated prior to their second laboratory visit. All participants were tested entirely separately from one another and remained sedentary in the laboratory throughout. Upon arrival at 08:00 $\pm 1 \mathrm{~h}$, following an overnight fast of $\geqslant 10 \mathrm{~h}$ duration, participants voided and then had body mass measured in light clothing
Table 1. Participant characteristics

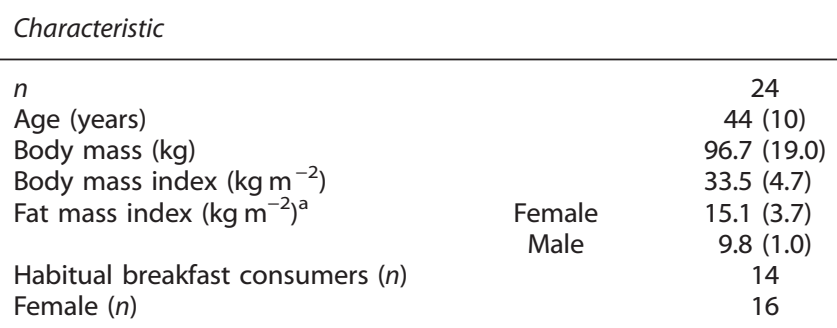

${ }^{\mathrm{a}}$ Fat mass index calculated as dual energy $\mathrm{X}$-ray absorptiometry-derived total fat mass divided by height squared. Values represent mean with (s.d.)

(Seca 873, Vogel and Halke). Resting metabolic rate was obtained according to guidelines for best practice. ${ }^{33,34}$ A cannula was then placed into an antecubital vein, with a $15 \mathrm{ml}$ baseline sample of blood drawn. Participants then either consumed a breakfast (to be finished within 15 $\mathrm{min}$ ) or were asked to rest for an equivalent period, with blood drawn at $15 \mathrm{~min}, 30 \mathrm{~min}$ and an hour after the completion of the breakfast/rest period. Blood samples were then drawn at hourly intervals until $3 \mathrm{~h}$ post breakfast, when an ad libitum lunch was served. The lunch period lasted 30 min with participants left alone during this time. Following lunch, blood samples were obtained at hourly intervals from $1 \mathrm{~h}$ after the end of lunch until $3 \mathrm{~h}$ after lunch. Throughout the day, participants completed visual analogue scales assessing appetite.

\section{Meal provision}

During the breakfast trial, the breakfast consisted of typical breakfast foods (that is, cereal with milk, toast and orange juice), in quantities providing $0.06 \mathrm{~g}$ carbohydrate per $\mathrm{kcal}$ of individually measured daily resting metabolic rate (energy content of breakfast $\sim 31 \%$ of resting metabolic rate) for each participant and provided $2183 \pm 393 \mathrm{~kJ}(521 \pm 94 \mathrm{kcal})$, as $70 \%$ carbohydrate, $17 \%$ fat and $13 \%$ protein. The ad libitum lunch participants consumed consisted of freshly cooked pasta with a tomatobased sauce, which provided $79 \%$ carbohydrate, $14 \%$ fat and $7 \%$ protein. This was provided in a large bowl, with the pasta topped up every $10 \mathrm{~min}$ to prevent visual feedback of food consumed and any tendency to finish the provided portion. The lunch meal was consumed alone and participants were played a recorded message asking them to eat until they had satisfied their hunger.

\section{Expired gas analysis}

Douglas bags were employed to obtain expired air samples with samples for resting metabolic rate collected in line with guidance for best practice. ${ }^{33,34}$ Rates of both oxygen utilisation $\left(\mathrm{V}_{2}\right)$ and carbon dioxide production $\left(\mathrm{V}_{\mathrm{CO}}\right)$ were used to calculate energy expenditure ${ }^{35}$ corrected for urinary nitrogen excretion: ${ }^{36}$

Energy expenditure $=\left(3.941 \times \dot{\mathrm{VO}}_{2}\right)+\left(1.106 \times \dot{\mathrm{V}} \mathrm{CO}_{2}\right)+(2.17 \times$ nitrogen excretion $)$.

\section{Blood sampling and analysis}

Blood was sampled via intravenous cannula inserted into veins of the antecubital region of the arm. Blood was collected and stored as serum or plasma using standard methods, apart from samples for analysis of acylated ghrelin, with blood treated to prevent degradation by proteases as described previously. ${ }^{21}$ Total ghrelin (intra-assay coefficient of variation (CV), 4.0\%, inter-assay CV, 7.8\%) and acylated ghrelin (intra-assay CV, $4.2 \%$, inter-assay CV, 11.3\%) (Bertin Pharma, Montigny le Bretonneux, France) and peptide tyrosine-tyrosine (PYY; intra-assay CV, 4.3\%, inter-assay CV, $11.1 \%$ ) assays were conducted using plasma. Leptin (intra-assay CV, 3.4\%, inter-assay CV, 6.4\%) (R\&D Systems Inc, Abingdon, UK) and insulin (intraassay CV, 4.7\%, inter-assay CV, 12.5\%) (Mercodia AB, Uppsala, Sweden) assays were conducted using serum. Assays employed were commercially available enzyme-linked immunosorbent assay conducted following manufacturer instructions, with all samples batch analysed upon study completion and samples from each participant assayed on the same plate. Plasma samples were analysed for non-esterified fatty acids (intra-assay $\mathrm{CV},<5 \%$, inter-assay CV, $<5 \%$ ), glucose (intra-assay $\mathrm{CV},<5 \%$, inter-assay 
$\mathrm{CV},<6 \%$ ) and urea (intra-assay CV, $<5 \%$, inter-assay CV, $<3 \%$ ) using a Daytona automated analyser (Randox Laboratories, Crumlin, NI, USA) according to manufacturer guidelines using commercially available immunoassays (Randox Laboratories).

\section{Urine collection}

Urine was collected in containers with $5 \mathrm{ml}$ of $10 \%$ thymol isopropanol used as a preservative. The urine collected during a measurement period was thoroughly mixed, and a $1-\mathrm{ml}$ aliquot abstracted and stored at $-80^{\circ} \mathrm{C}$. Urinary urea concentrations for use in calculations to determine urinary nitrogen excretion were established using a commercially available immunoassay as described above for plasma.

\section{Appetite sensations}

Paper visual analogue scales of 100-mm length were employed to assess subjective appetite. These scales were completed pre- and post breakfast, pre- and post lunch and following a $3 \mathrm{~h}$ postprandial period after lunch. Participants marked a response to questions assessing desire to eat, hunger, fullness and prospective consumption with anchor phrases on the ends of each of the scales (for example, not at all hungry vs as hungry as I have ever felt). Higher scores are indicative of greater sensations. A composite appetite score ${ }^{37}$ was calculated using the following formula:

(desire to eat+hunger+(100 - fullness)+prospective consumption)/4.

\section{Statistical analysis}

For single comparisons of two means (for example, energy intake at lunch), data were verified as normally distributed using a Shapiro-Wilk test and paired $t$-tests were used for parametric data. For comparison of variables measured throughout the day in each condition (for example, appetite hormones), repeated measures analysis of variance (breakfast/fasting $\times$ time point) were conducted with the application of Greenhouse-Geisser corrections to intra-individual contrasts for $\varepsilon<0.75$, and the Huynh-Feldt correction employed for less-severe asphericity. ${ }^{38}$ Significant interactions were explored using multiple $t$-tests to locate differences between trials at specific time-points, with a Holm-Bonferroni stepwise adjustment employed. ${ }^{39}$ Statistical significance was accepted at $P \leqslant 0.05$. Data are presented in text as mean \pm s.d.; with figures displaying mean with normalised confidence intervals. These confidence intervals show the comparison between the two trials at each time point, removing interindividual variation due to the fully paired experimental design. ${ }^{40}$ Statistical analyses were conducted using IBM SPSS statistics version 22 (IBM, New York, NY, USA).

\section{RESULTS}

Energy intake

Energy intake at the ad libitum lunch was $3638 \pm 1480 \mathrm{~kJ}$ $(869 \pm 354 \mathrm{kcal})$ in the fasting trial and was not significantly different to the breakfast trial $(3419 \pm 1360 \mathrm{~kJ}, 817 \pm 325 \mathrm{kcal}$; $P=0.1$, Figure 1). The additional intake at lunch during the fasting trial accounted for $10 \%$ of the intake provided with breakfast, resulting in a lower absolute intake over the testing day of $1964 \mathrm{~kJ}$ (469 kcal) (95\% confidence interval $-1645 \mathrm{~kJ},-2281 \mathrm{~kJ} ; P<0.01$ ) during the fasting trial.

Glucose

There were main effects of trial and time, and an interaction of trial $\times$ time for plasma glucose (all $P<0.01$ ). Blood glucose was lower during the fasting trial until $2 \mathrm{~h}$ post breakfast (all $P<0.01$; Figure 2a) but was not different $3 \mathrm{~h}$ after breakfast $(P=0.26)$. Blood glucose concentrations were greater in the fasting trial $1 \mathrm{~h}$ after lunch $(P<0.01)$ but not throughout the rest of the afternoon (both $P>0.1$ ).

Insulin

There were main effects of time, trial and a trial $\times$ time interaction for serum insulin concentrations (all $P<0.02$ ). Insulin concentrations

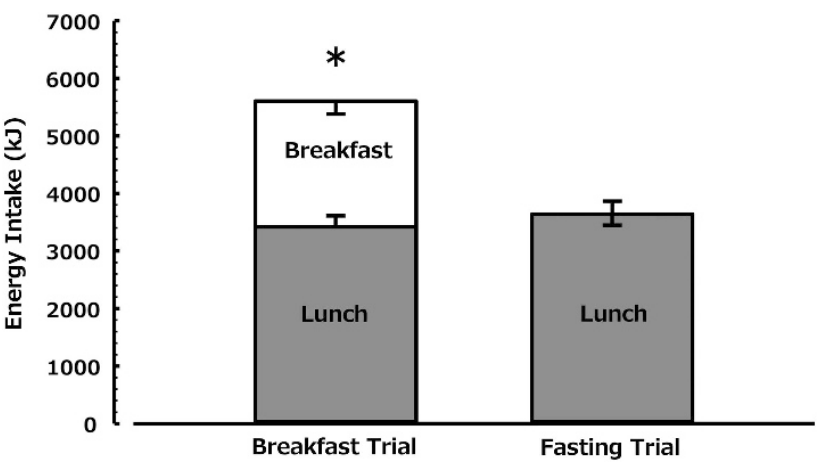

Figure 1. Energy intake during trials. In the morning fasting trial an asymmetric confidence interval is plotted, the negative portion of which reflects the comparison between lunches and the positive portion reflects the comparison against total intake (that is, lunch plus breakfast). An asterisk above a bar represents the comparison between the total intake in the two trials $(n=24),{ }^{*} P<0.01$.

were lower throughout the morning during the fasting trial (all $P<0.02$, Figure $2 \mathrm{~b}$ ). However, after the ad libitum lunch, insulin concentrations were greater in the fasting trial (all $P=0.05$ ).

Non-esterified fatty acids

Main effects of time and trial were evident for plasma nonesterified fatty acids as well as a time $\times$ trial interaction (all $P<0.01$ ). Non-esterified fatty acids concentrations were higher in the fasting trial throughout the morning (all $P<0.05$, Figure 2c). There was a statistically significant but quantitatively small difference $2 \mathrm{~h}$ after lunch consumption (fasting; $0.05 \pm 0.02$ $\mathrm{mmolI}^{-1}$ vs Breakfast; $0.08 \pm 0.06 \mathrm{mmol}^{-1} ; P=0.04$ ), with no differences between non-esterified fatty acids concentrations in the two trials at 1 and $3 \mathrm{~h}$ after lunch (both $P>0.1$ ).

\section{Acylated ghrelin}

A main effect of time and a trial $\times$ time interaction (both $P<0.01$ ) were apparent for plasma-acylated ghrelin concentrations. Acylated ghrelin concentrations were higher in the fasting trial until $2 \mathrm{~h}$ post breakfast (both $P<0.01$; Figure $3 \mathrm{a}$ ), with no difference between the trials immediately prior to the ad libitum lunch $(P=0.47)$. Following lunch consumption, acylated ghrelin was lower throughout the afternoon in the fasting trial $(P<0.01)$.

\section{Total ghrelin}

There were main effects of trial, time and a trial $\times$ time interaction (all $P<0.01$ ) for total ghrelin concentrations. Total ghrelin concentrations were significantly higher in the fasting trial throughout the morning (all $P<0.04$, Figure 3b). Following lunch consumption, there was no difference between total ghrelin concentrations in the two trials.

PYY

Plasma concentrations of PYY differed over time, between trials and there was a trial $\times$ time interaction evident (all $P<0.01$; Figure $3 \mathrm{c}$ ), with lower concentrations in the fasting trial (all $P<0.02$ ) until $2 \mathrm{~h}$ after lunch. Three hours after lunch consumption, the difference between trials was reduced such that there was only a strong tendency for lower concentrations in the fasting trial $(P=0.06)$.

Leptin

For serum leptin concentrations there were main effects of trial, time and a significant trial $\times$ time interaction (all $P<0.04$; 

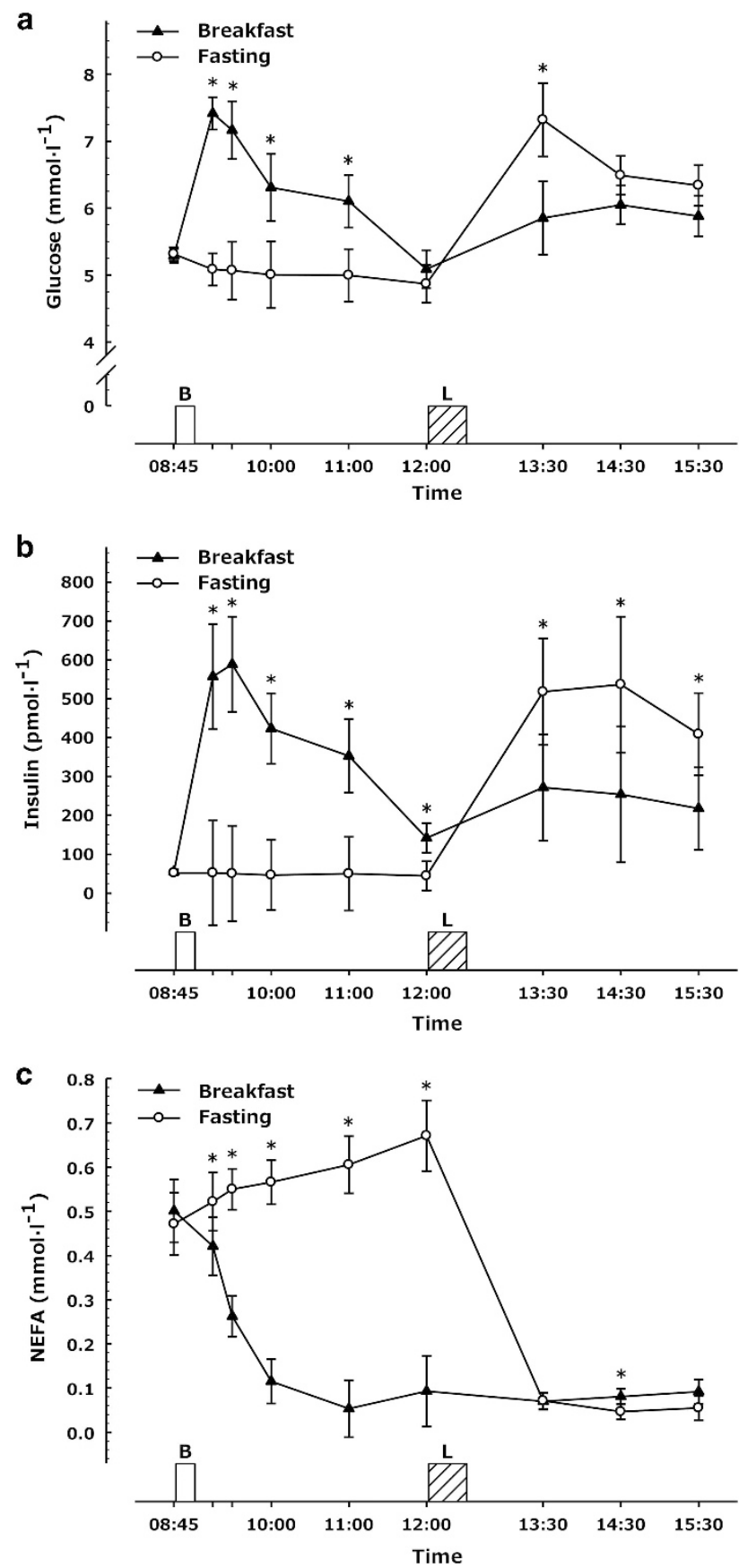

Figure 2. Metabolic responses during trials (a) plasma glucose, (b) serum insulin, (c) plasma NEFA, (all measures $n=18$ ) where missing data is owing to insufficient blood for analysis. Values represent mean $\pm \mathrm{nCl} .{ }^{*} P \leqslant 0.05$ versus corresponding time point in other trial. Annotations on figure represent the following, $\mathrm{B}=$ Breakfast period, in which participants ate a prescribed breakfast during the breakfast trial and rested during the morning fasting trial. $\mathrm{L}=$ Ad libitum pasta lunch.

Figure 3d). Leptin concentrations decreased pre-lunch in both groups, but with a strong tendency for lower concentrations in the fasting trial (fasting trial, $21.3 \mathrm{ng} \mathrm{ml}^{-1}$ vs breakfast trial, $24.1 \mathrm{ng} \mathrm{ml}^{-1}, P=0.06$ ). Three hours after lunch consumption, leptin concentrations were significantly lower in the fasting trial $\left(21.5 \pm 15.3 \mathrm{ng} \mathrm{ml}^{-1}\right)$ than the breakfast consumption trial $\left(29.1 \pm 23.0 \mathrm{ng} \mathrm{ml}^{-1} ; P<0.01\right)$.
Subjective appetite ratings

For the composite appetite score calculated (Figure 4) there was a main effect of trial, time and a trial $\times$ time interaction (all $P<0.03$ ). Appetite was greater in the fasting trial throughout the morning (both $P<0.01)$. There was no difference in appetite immediately after lunch consumption $(P=0.15)$ but there was a slight tendency for lesser appetite at the end of the testing day in the fasting trial (35 \pm 17 vs $41 \pm 17 ; P=0.09$ ).

\section{DISCUSSION}

The current study characterised the metabolic, hormonal and appetite responses to extended morning fasting in obese individuals. We have demonstrated for the first time that obese individuals do not compensate for missed breakfast energy intake at a lunchtime meal and that neither ghrelin nor subjective measures of appetite are increased during the afternoon following morning fasting.

This is the first study to specifically examine a contrast of acute morning fasting against breakfast consumption on ad libitum lunch intake in obese individuals. Although it has been suggested that energy intake is increased with breakfast skipping ${ }^{41}$ there is accumulating evidence from randomised controlled trials that energy intake is either unaffected ${ }^{42}$ or lower in individuals who skip breakfast. ${ }^{43,44}$ The current study indicates that any potential compensation for omitted energy intake through breakfast skipping is not strongly manifested through energy intake at this lunchtime meal in obese individuals. This is in contrast to lean individuals previously studied using the same experimental design, ${ }^{21}$ where it was established that energy intake at lunch was significantly increased after morning fasting (although insufficiently to compensate for the omitted breakfast). It therefore appears that increased adiposity results in similar lunch time food intake independent of morning feeding and eradicates the immediate compensatory feeding responses apparent in lean individuals.

It has previously been shown that ghrelin suppression by food intake is either reduced ${ }^{29}$ or abolished ${ }^{30}$ in obese individuals, yet in the present study ghrelin was suppressed by breakfast consumption in that trial, and by lunch intake in the morning fasting trial. This indicates that ghrelin suppression does occur in obese individuals and occurs independent of the overnight fast duration. However, similar to our previous observations in lean individuals, ${ }^{21}$ a prior carbohydrate-rich breakfast meal can interfere with subsequent ghrelin suppression by a similarly carbohydrate-rich ad libitum lunch. This blunted response of ghrelin during the afternoon (that is, a lack of suppression after feeding) may be linked to reduced insulin responses to the lunch following breakfast consumption that is putatively due to the second-meal effect ${ }^{45,46}$ as some authors have proposed an important role for insulin in ghrelin suppression. ${ }^{47-49}$ Whether this effect persists with breakfast and lunchtime meal combinations inducing less-pronounced differences in insulinaemia relative to morning fasting is an interesting area of future study.

Leptin and PYY concentrations were lower in the afternoon during the fasting trial; as would be expected for both hormones due to the stimulatory effects of repeated feeding ${ }^{50,51}$ and the proposed mediating role of PYY in signalling relative energy deficit from calorie restriction. ${ }^{52}$ Therefore, in individuals who had fasted during the morning, there were hormonal responses following lunch generally associated with reduced satiety (lower PYY/leptin) as well as others that may contribute to reduced hunger (lower ghrelin). Within the context of these contrasting hormonal responses, there was some tentative evidence of lower perceptions of appetite at the end of the day in the fasting trial in these obese individuals. Future work extending laboratory investigations into the evening would provide interesting 

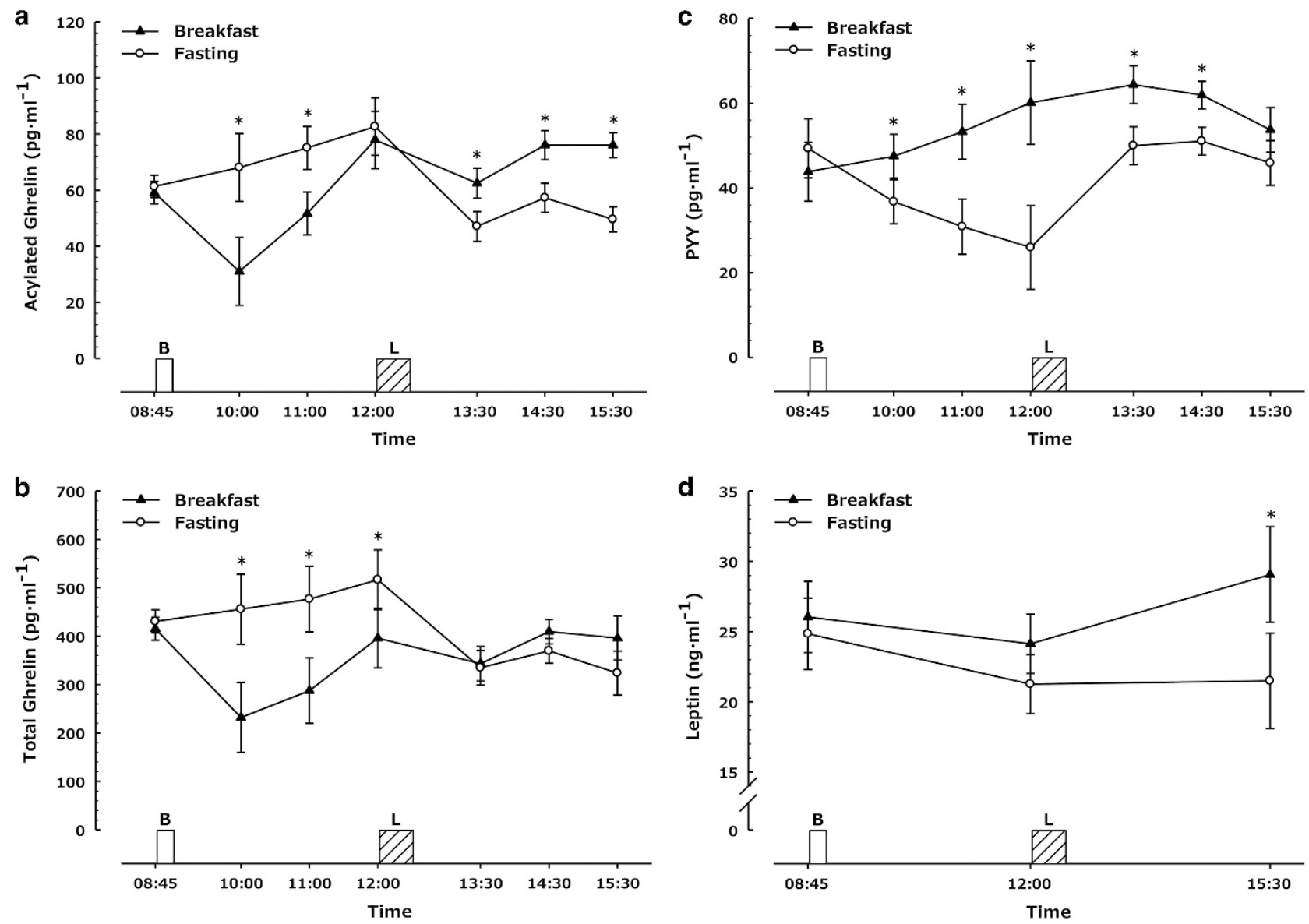

Figure 3. Hormonal responses during trials (a) plasma-acylated ghrelin, (b) plasma total ghrelin, (c) plasma PYY, (d) serum leptin, (all measures $n=18$ ) where missing data is because of insufficient blood for analysis. Values represent mean $\pm \mathrm{nCl}$. ${ }^{*} P<0.05$ versus corresponding time point in other trial. Annotations on figure represent the following, B = Breakfast period, in which participants ate a prescribed breakfast during the breakfast trial and rested during the morning fasting trial. $L=$ Ad libitum pasta lunch.

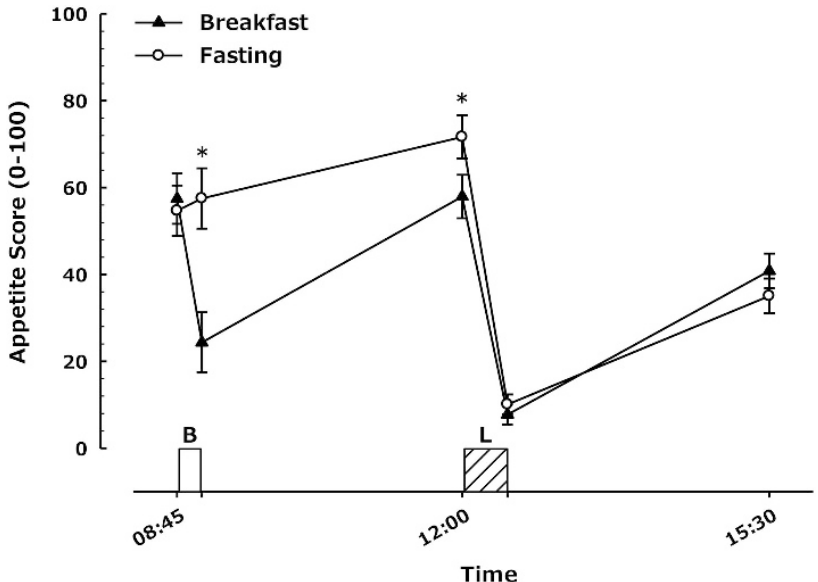

Figure 4. Appetite score during trials. $(n=24)$, values represent mean $\pm \mathrm{nCl}$. ${ }^{*} P<0.01$ versus corresponding time point in other trial. Annotations on figure represent the following, $B=$ Breakfast period, in which participants ate a prescribed breakfast during the breakfast trial and rested during the morning fasting trial. $\mathrm{L}=$ Ad libitum pasta lunch.

information as to the time course of these hormones/subjective perceptions of appetite prior to a $2 \mathrm{nd} / 3 \mathrm{rd}$ meal and establish if there are any resultant effects upon total daily energy intake in obese individuals. As it has recently been suggested that the circadian clock increases appetite and hunger in the evening independent of food intake, ${ }^{53}$ it would be informative to establish if different morning feeding patterns can influence appetite later in the day imposed upon this underlying circadian rhythmicity. As two recent publications examining morning fasting in lean individuals have reported insufficient ad libitum intake at multiple subsequent meals to compensate for breakfast consumption, ${ }^{18,22}$ it is of interest to establish the effect of morning fasting upon cumulative intake across several meals in obese individuals.

Despite marked differences in subjective ratings of appetite immediately prior to lunch, there was no difference in lunchtime energy intake between the two trials. This is not completely unexpected as the correlation between pre-lunch appetite ratings and ad libitum lunch energy intake in lean men is modest at best (that is, $r=0.25-0.38)^{54}$ and a meta-analysis has indicated that sensations of hunger and satiety do not correlate with energy intake in obese individuals. ${ }^{55}$ There are several plausible explanations for this lack of relationship between pre-lunch appetite ratings and energy intake. First, that the relationship between appetite and intake is disrupted in obese individuals. ${ }^{55}$ Second, that subjective appetite measures do not adequately capture the various dimensions of appetite. ${ }^{56}$ Third, there is evidence that people eat according to habit ${ }^{57,58}$ and it is possible that the current intervention is not potent enough to overcome these feeding habits. Lastly, that another factor led to termination of the meal in participants who were still hungry. This could have arisen owing to feelings other than satiation (that is, boredom and reduced liking for the food provided due to the homogeneity of 
the meal provided in this fixed course meal), as provision of a variety of foods delays satiation ${ }^{59}$ and promotes greater intake. ${ }^{60,61}$

Examination of feeding behaviours within the laboratory allows tight experimental control of participants and measurements of physiological parameters that may influence, and are affected by, food intake. However, it is plausible that energy intake in a natural environment would be discrepant from the results obtained in the laboratory owing to self-regulation of feeding patterns and food choices. This is also particularly relevant as obese individuals display elevated neural responses to palatable and energy-dense foods ${ }^{62}$ and are suggested to be more susceptible to environmental cues to eat than hormonal regulation. ${ }^{63,64}$ Laboratory studies utilising buffet designs or permitting volitional feeding frequency are warranted in obese individuals as well as free-living studies examining energy intake.

The present study demonstrates extended morning fasting does not result in compensatory intake at an ad libitum lunch meal in obese individuals. We have shown for the first time that morning fasting does not interfere with the suppression of ghrelin by a lunch in obese individuals, potentially because of the greater insulin response when consuming the meal fasted. There was also no evidence of increased appetite in the afternoon when individuals had fasted throughout the morning. These results indicate that obese individuals do not compensate for morning fasting by consuming more food at the next meal but that hormonal and metabolic responses to lunch are impacted by morning feeding.

\section{CONFLICT OF INTEREST}

The authors declare no conflict of interest.

\section{ACKNOWLEDGEMENTS}

We are grateful to all of those that participated in the study. This research is funded by the British Biotechnology and Biological Sciences Research Council (BBSRC). EAC received a University Research Scholarship from the University of Bath. This study is registered with Current Controlled Trials (ISRCTN31521726).

\section{DATA ARCHIVING}

All data created during this research are openly available from the University of Bath data archive at http://dx.doi.org/10.15125/BATH-00133.

\section{AUTHOR CONTRIBUTIONS}

$J A B, D T$, JDR, EAC and KT designed research; JDR, EAC, JAB and DT conducted research; $E A C, J A B$ and JDR analysed the data and performed statistical analysis; EAC wrote the paper; JAB had primary responsibility for the final content. All authors read, edited and approved the final manuscript.

\section{REFERENCES}

1 Ma Y, Bertone ER, Stanek 3rd EJ, Reed GW, Hebert JR, Cohen NL et al. Association between eating patterns and obesity in a free-living US adult population. Am J Epidemiol 2003; 158: 85-92.

2 Horikawa C, Kodama S, Yachi Y, Heianza Y, Hirasawa R, lbe $Y$ et al. Skipping breakfast and prevalence of overweight and obesity in Asian and Pacific regions: a meta-analysis. Prev Med 2011; 53: 260-267.

3 Purslow LR, Sandhu MS, Forouhi N, Young EH, Luben RN, Welch AA et al. Energy intake at breakfast and weight change: prospective study of 6,764 middle-aged men and women. Am J Epidemiol 2008; 167: 188-192.

4 Mekary RA, Giovannucci E, Cahill L, Willett WC, van Dam RM, Hu FB. Eating patterns and type 2 diabetes risk in older women: breakfast consumption and eating frequency. Am J Clin Nutr 2013; 98: 436-443.

5 Mekary RA, Giovannucci E, Willett WC, van Dam RM, Hu FB. Eating patterns and type 2 diabetes risk in men: breakfast omission, eating frequency, and snacking. Am J Clin Nutr 2012; 95: 1182-1189.
6 Cahill LE, Chiuve SE, Mekary RA, Jensen MK, Flint AJ, Hu FB et al. Prospective study of breakfast eating and incident coronary heart disease in a cohort of male US health professionals. Circulation 2013; 128: 337-343.

7 Dhurandhar EJ, Dawson J, Alcorn A, Larsen LH, Thomas EA, Cardel M et al. The effectiveness of breakfast recommendations on weight loss: a randomized controlled trial. Am J Clin Nutr 2014; 100: 507-513.

8 Geliebter A, Astbury NM, Aviram-Friedman R, Yahav E, Hashim S. Skipping breakfast leads to weight loss but also elevated cholesterol compared with consuming daily breakfasts of oat porridge or frosted cornflakes in overweight individuals:a randomised controlled trial. J Nutr Sci 2014; 3: e56.

9 Dhurandhar NV, Schoeller D, Brown AW, Heymsfield SB, Thomas D, Sorensen TI et al. Energy balance measurement: when something is not better than nothing. Int J Obes (Lond) 2014; 39: 1109-1113.

10 Clegg M, Shafat A. Energy and macronutrient composition of breakfast affect gastric emptying of lunch and subsequent food intake, satiety and satiation. Appetite 2010; 54: 517-523.

11 Hamedani A, Akhavan T, Samra RA, Anderson GH. Reduced energy intake at breakfast is not compensated for at lunch if a high-insoluble-fiber cereal replaces a low-fiber cereal. Am J Clin Nutr 2009; 89: 1343-1349.

12 Kim H, Stote KS, Behall KM, Spears K, Vinyard B, Conway JM. Glucose and insulin responses to whole grain breakfasts varying in soluble fiber, beta-glucan: a dose response study in obese women with increased risk for insulin resistance. Eur J Nutr 2009; 48: 170-175.

13 Levine AS, Tallman JR, Grace MK, Parker SA, Billington CJ, Levitt MD. Effect of breakfast cereals on short-term food intake. Am J Clin Nutr 1989; 50: 1303-1307.

14 Liljeberg HG, Akerberg AK, Bjorck IM. Effect of the glycemic index and content of indigestible carbohydrates of cereal-based breakfast meals on glucose tolerance at lunch in healthy subjects. Am J Clin Nutr 1999; 69: 647-655.

15 Martin A, Normand S, Sothier M, Peyrat J, Louche-Pelissier C, Laville M. Is advice for breakfast consumption justified? Results from a short-term dietary and metabolic experiment in young healthy men. $\mathrm{Br} J$ Nutr 2000; 84: 337-344.

16 Rosen LA, Ostman EM, Bjorck IM. Effects of cereal breakfasts on postprandial glucose, appetite regulation and voluntary energy intake at a subsequent standardized lunch; focusing on rye products. Nutr J 2011; 10: 7 .

17 Nilsson AC, Ostman EM, Granfeldt Y, Bjorck IM. Effect of cereal test breakfasts differing in glycemic index and content of indigestible carbohydrates on daylong glucose tolerance in healthy subjects. Am J Clin Nutr 2008; 87: 645-654.

18 Levitsky DA, Pacanowski CR. Effect of skipping breakfast on subsequent energy intake. Physiol Behav 2013; 119: 9-16.

19 Gonzalez JT, Veasey RC, Rumbold PL, Stevenson EJ. Breakfast and exercise contingently affect postprandial metabolism and energy balance in physically active males. Br J Nutr 2013; 1-12.

20 Astbury NM, Taylor MA, Macdonald IA. Breakfast consumption affects appetite, energy intake, and the metabolic and endocrine responses to foods consumed later in the day in male habitual breakfast eaters. J Nutr 2011; 141: 1381-1389.

21 Chowdhury EA, Richardson JD, Tsintzas K, Thompson D, Betts JA. Carbohydraterich breakfast attenuates glycaemic, insulinaemic and ghrelin response to ad libitum lunch relative to morning fasting in lean adults. Br J Nutr 2015; 114 : 98-107.

22 Clayton DJ, Barutcu A, Machin C, Stensel DJ, James LJ. Effect of breakfast omission on energy intake and evening exercise performance. Med Sci Sports Exerc 2015; e-pub ahead of print 12 May 2015.

23 Thomas EA, Higgins J, Bessesen DH, McNair B, Cornier MA. Usual breakfast eating habits affect response to breakfast skipping in overweight women. Obesity (Silver Spring) 2015; 23: 750-759.

24 Delgado-Aros S, Cremonini F, Castillo JE, Chial HJ, Burton DD, Ferber I et al. Independent influences of body mass and gastric volumes on satiation in humans. Gastroenterology 2004; 126: 432-440.

25 Batterham RL, Cowley MA, Small CJ, Herzog H, Cohen MA, Dakin CL et al. Gut hormone PYY(3-36) physiologically inhibits food intake. Nature 2002; 418: 650-654.

26 Batterham RL, Cohen MA, Ellis SM, Le Roux CW, Withers DJ, Frost GS et al. Inhibition of food intake in obese subjects by peptide YY3-36. N Engl J Med 2003; 349: $941-948$

27 le Roux CW, Batterham RL, Aylwin SJ, Patterson M, Borg CM, Wynne KJ et al. Attenuated peptide $Y Y$ release in obese subjects is associated with reduced satiety. Endocrinology 2006; 147: 3-8.

28 Cummings DE, Purnell JQ, Frayo RS, Schmidova K, Wisse BE, Weigle DS. A preprandial rise in plasma ghrelin levels suggests a role in meal initiation in humans. Diabetes 2001; 50: 1714-1719.

29 le Roux CW, Patterson M, Vincent RP, Hunt C, Ghatei MA, Bloom SR. Postprandial plasma ghrelin is suppressed proportional to meal calorie content in normalweight but not obese subjects. J Clin Endocrinol Metab 2005; 90: 1068-1071.

30 English PJ, Ghatei MA, Malik IA, Bloom SR, Wilding JP. Food fails to suppress ghrelin levels in obese humans. J Clin Endocrinol Metab 2002; 87: 2984. 
31 Kelly TL, Wilson KE, Heymsfield SB. Dual energy X-Ray absorptiometry body composition reference values from NHANES. PLoS One 2009; 4: e7038.

32 Betts JA, Thompson D, Richardson JD, Chowdhury EA, Jeans M, Holman GD et al. Bath Breakfast Project (BBP)--examining the role of extended daily fasting in human energy balance and associated health outcomes: study protocol for a randomised controlled trial [ISRCTN31521726]. Trials 2011; 12: 172.

33 Compher C, Frankenfield D, Keim N, Roth-Yousey L. Best practice methods to apply to measurement of resting metabolic rate in adults: a systematic review. J Am Diet Assoc 2006; 106: 881-903.

34 Betts JA, Thompson D. Thinking outside the bag (not necessarily outside the lab). Med Sci Sports Exerc 2012; 44: 2040, author reply 2041.

35 Weir JB. New methods for calculating metabolic rate with special reference to protein metabolism. J Physiol 1949; 109: 1-9.

36 Jequier E, Acheson K, Schutz Y. Assessment of energy expenditure and fuel utilization in man. Annu Rev Nutr 1987; 7: 187-208.

37 Anderson GH, Catherine NL, Woodend DM, Wolever TM. Inverse association between the effect of carbohydrates on blood glucose and subsequent shortterm food intake in young men. Am J Clin Nutr 2002; 76: 1023-1030.

38 Atkinson G. Analysis of repeated measurements in physical therapy research: multiple comparisons amongst level means and multi-factorial designs. Phys Ther Sport 2002; 3: 191-203.

39 Ludbrook J. Multiple comparison procedures updated. Clin Exp Pharmacol Physiol 1998; 25: 1032-1037.

40 Loftus GR, Masson ME. Using confidence intervals in within-subject designs. Psychon Bull Rev 1994; 1: 476-490.

41 Farshchi HR, Taylor MA, Macdonald IA. Deleterious effects of omitting breakfast on insulin sensitivity and fasting lipid profiles in healthy lean women. Am J Clin Nutr 2005; 81: 388-396.

42 Halsey LG, Huber JW, Low T, Ibeawuchi C, Woodruff P, Reeves S. Does consuming breakfast influence activity levels? An experiment into the effect of breakfast consumption on eating habits and energy expenditure. Public Health Nutr 2012; 15: $238-245$.

43 Reeves S, Huber JW, Halsey LG, Horabady-Farahani Y, ljadi M, Smith T. Experimental manipulation of breakfast in normal and overweight/obese participants is associated with changes to nutrient and energy intake consumption patterns. Physiol Behav 2014; 133: 130-135.

44 Betts JA, Richardson JD, Chowdhury EA, Holman GD, Tsintzas K, Thompson D. The causal role of breakfast in energy balance and health: a randomized controlled trial in lean adults. Am J Clin Nutr 2014; 100: 539-547.

45 Bonuccelli S, Muscelli E, Gastaldelli A, Barsotti E, Astiarraga BD, Holst JJ et al. Improved tolerance to sequential glucose loading (Staub-Traugott effect): size and mechanisms. Am J Physiol Endocrinol Metab 2009; 297: E532-E537.

46 Hamman L, Hirschmann I. Studies on blood sugar; IV. Effects upon the blood sugar of the repeated ingestion of glucose. Johns Hopkins Hosp Bull 1919; 30: 306-307.

47 Flanagan DE, Evans ML, Monsod TP, Rife F, Heptulla RA, Tamborlane WV et al. The influence of insulin on circulating ghrelin. Am J Physiol Endocrinol Metab 2003; 284: E313-E316.

48 Murdolo G, Lucidi P, Di Loreto C, Parlanti N, De Cicco A, Fatone C et al. Insulin is required for prandial ghrelin suppression in humans. Diabetes 2003; 52: 2923-2927.
49 Saad MF, Bernaba B, Hwu CM, Jinagouda S, Fahmi S, Kogosov E et al. Insulin regulates plasma ghrelin concentration. J Clin Endocrinol Metab 2002; 87: 3997-4000.

50 Hill BR, De Souza MJ, Williams NI. Characterization of the diurnal rhythm of peptide $\mathrm{YY}$ and its association with energy balance parameters in normal-weight premenopausal women. Am J Physiol Endocrinol Metab 2011; 301: E409-E415.

51 Saad MF, Riad-Gabriel MG, Khan A, Sharma A, Michael R, Jinagouda SD et al. Diurnal and ultradian rhythmicity of plasma leptin: effects of gender and adiposity. J Clin Endocrinol Metab 1998; 83: 453-459.

52 King JA, Wasse LK, Ewens J, Crystallis K, Emmanuel J, Batterham RL et al. Differential acylated ghrelin, peptide YY3-36, appetite, and food intake responses to equivalent energy deficits created by exercise and food restriction. J Clin Endocrinol Metab 2011; 96: 1114-1121.

53 Scheer FA, Morris CJ, Shea SA. The internal circadian clock increases hunger and appetite in the evening independent of food intake and other behaviors. Obesity (Silver Spring) 2013; 21: 421-423.

54 Flint A, Raben A, Blundell JE, Astrup A. Reproducibility, power and validity of visual analogue scales in assessment of appetite sensations in single test meal studies. Int J Obes Relat Metab Disord 2000; 24: 38-48.

55 Flint A, Gregersen NT, Gluud LL, Moller BK, Raben A, Tetens I et al. Associations between postprandial insulin and blood glucose responses, appetite sensations and energy intake in normal weight and overweight individuals: a meta-analysis of test meal studies. Br J Nutr 2007; 98: 17-25.

56 Mattes RD, Hollis J, Hayes D, Stunkard AJ. Appetite: measurement and manipulation misgivings. J Am Diet Assoc 2005; 105: S87-S97.

57 Cohen D, Farley TA. Eating as an automatic behavior. Prev Chronic Dis 2008; 5: A23.

58 Tuomisto T, Tuomisto MT, Hetherington M, Lappalainen R. Reasons for initiation and cessation of eating in obese men and women and the affective consequences of eating in everyday situations. Appetite 1998; 30: 211-222.

59 Hetherington MM, Foster R, Newman T, Anderson AS, Norton G. Understanding variety: tasting different foods delays satiation. Physiol Behav 2006; 87: 263-271.

60 Rolls BJ, Rowe EA, Rolls ET, Kingston B, Megson A, Gunary R. Variety in a meal enhances food intake in man. Physiol Behav 1981; 26: 215-221.

61 Spiegel TA, Stellar E. Effects of variety on food intake of underweight, normalweight and overweight women. Appetite 1990; 15: 47-61.

62 Burger KS, Berner LA. A functional neuroimaging review of obesity, appetitive hormones and ingestive behavior. Physiol Behav 2014; 136: 121-127.

63 Schachter S. Obesity and eating. Internal and external cues differentially affect the eating behavior of obese and normal subjects. Science 1968; 161: 751-756.

64 Mela DJ. Determinants of food choice: relationships with obesity and weight control. Obes Res 2001; 9(Suppl 4): 249S-255S.

This work is licensed under a Creative Commons Attribution 4.0 International License. The images or other third party material in this article are included in the article's Creative Commons license, unless indicated otherwise in the credit line; if the material is not included under the Creative Commons license, users will need to obtain permission from the license holder to reproduce the material. To view a copy of this license, visit http://creativecommons.org/licenses/ by/4.0/ 